\title{
Bridge-to-surgery gallbladder drainage with a lumen-apposing metal stent in malignant distal biliary obstruction: a choice tailored for the surgeon
}

A 70-year-old woman with cholangitis was diagnosed with a distal biliary stricture at another institution. The patient was referred to our center for biliary decompression and further evaluation.

Endoscopic ultrasound (EUS) examination revealed wall thickening in the lower third of the common bile duct (CBD) and an intraluminal inhomogeneous hypoechoic lesion with irregular margins infiltrating the duodenal wall and the major papilla ( $\mathbf{F i g . 1}$ ). The gallbladder was distended, and the middle/upper third of the CBD was dilated up to $2 \mathrm{~cm}$ in diameter, with associated intrahepatic biliary tree dilation. Endoscopic retrograde cholangiopancreatography (ERCP) was unsuccessful owing to duodenal infiltration.

In order not to hamper a theoretical subsequent surgical bilioenteric anastomosis (in the setting of a duodenopancreatectomy) we decided not to proceed with EUS-guided bile duct drainage (EUS-BD), even if technically feasible. In fact, an EUS-guided choledochoduodenostomy would have altered the integrity of the middle/upper third of the CBD, potentially conditioning future surgery, in case of resectability. Considering this, we opted for EUS-guided gallbladder drainage (EUS-GDB) from the gastric antrum with an $8 \times 8 \mathrm{~mm}$ electrocauterytipped lumen-apposing metal stent (LAMS) (AXIOS-EC; Boston Scientific, Marlborough, Massachusetts, USA) in a freehand fashion.

Same-session EUS-guided fine-needle biopsy confirmed malignancy of the lesion and a computed tomography scan assessed resectability ( $>$ Fig. 2 ). The patient underwent Whipple duodenopancreatectomy 2 weeks later ( $\triangleright$ Fig. $\mathbf{3 a , b}$, - Video 1). Histologic assessment diagnosed a PT2 /N2 /Pn1/R0 poorly differentiated adenocarcinoma, and the postoperative course was uneventful.

EUS-GBD has been described as an effective rescue treatment following failed

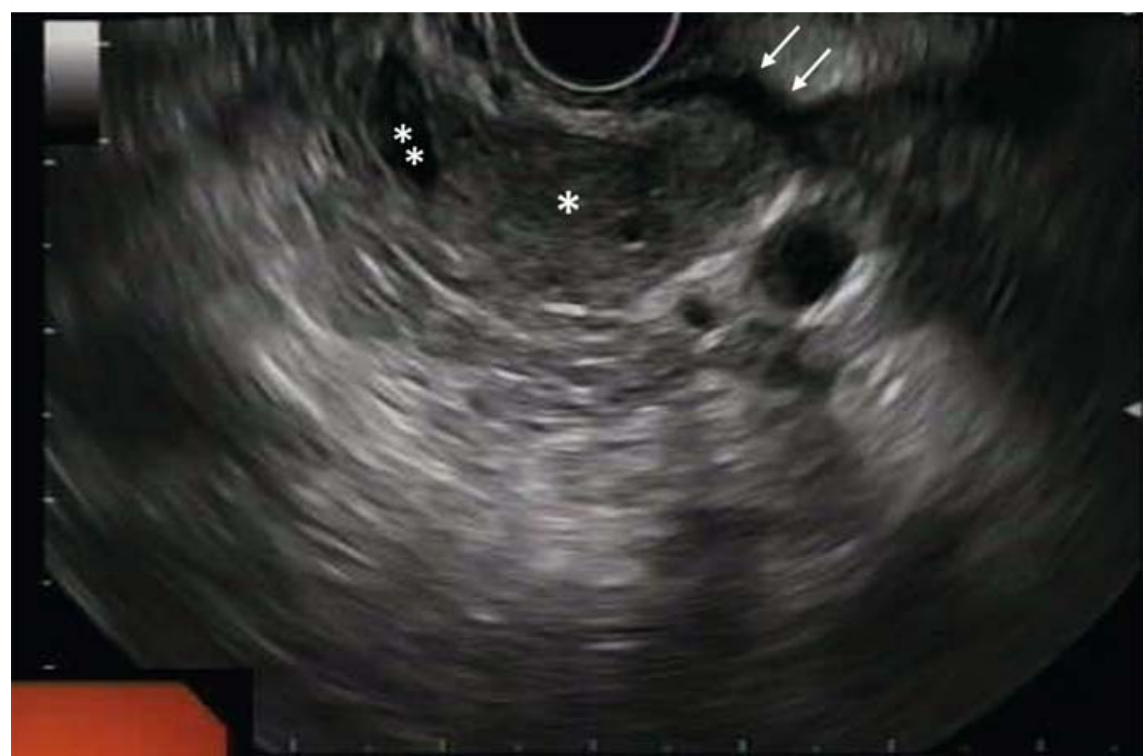

- Fig. 1 Endoscopic ultrasound view of the lesion $\left({ }^{*}\right)$ at the lower third of the common bile duct (CBD) showing infiltration of the duodenal wall (arrows). The lumen of the CBD $\left({ }^{* *}\right)$ is visible above the lesion.
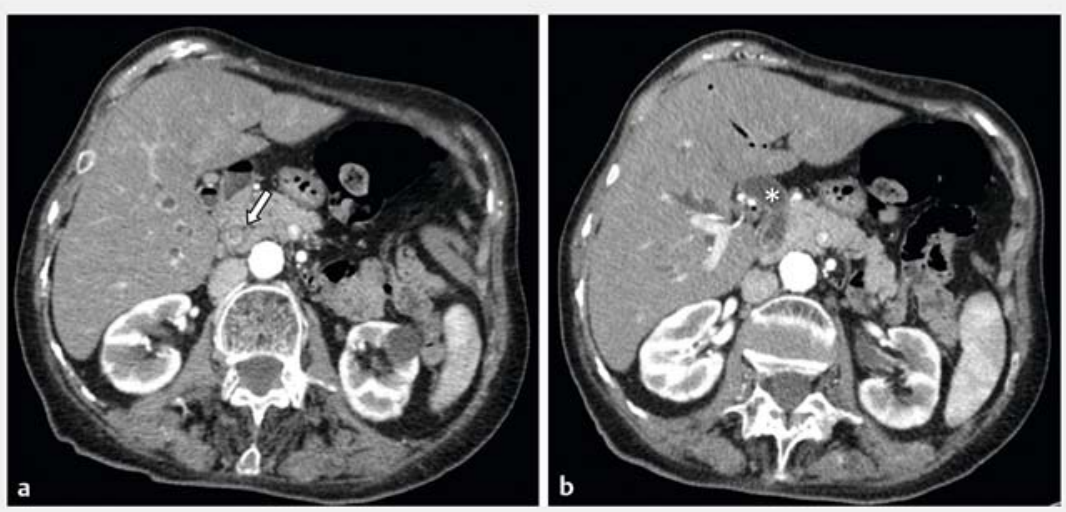

- Fig. 2 Contrast-enhanced computed tomography scan. a Intraluminal hyperenhancing tissue of the distal part of the common bile duct (CBD) (arrow). b Dilation of the upper/ middle third of the CBD $\left({ }^{*}\right)$.

ERCP and EUS-BD in patients with unresectable distal biliary stricture [1]. In resectable malignant distal biliary strictures, EUS-GBD using an LAMS is a feasible bridge-to-surgery treatment if biliary decompression is needed. Actually, this technique preserves the integrity of the
$\mathrm{CBD}$, allowing the surgeon to perform a standard Whipple resection and a safe bilioenteric anastomosis.

Endoscopy_UCTN_Code_TTT_1AS_2AG 


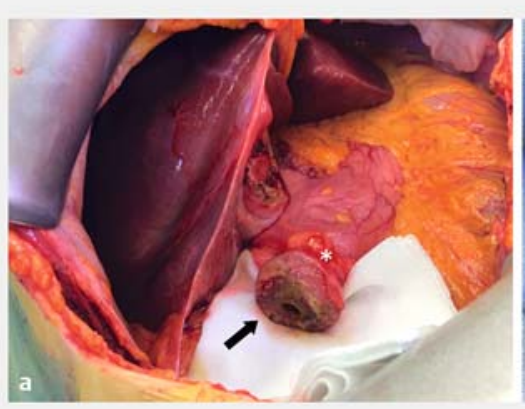

- Fig. 3 Whipple duodenopancreatectomy. a Intraoperative view of the cholecystogastrostomy $\left({ }^{*}\right)$. The proximal flange of the lumen-apposing metal stent (LAMS) can be seen (arrow). b Surgical specimen showing the proximal flange of the LAMS (arrow), gastric antrum ( ${ }^{*}$ ), first $\left({ }^{* *}\right)$ and second $\left({ }^{* * *}\right)$ portion of the duodenum, and head of the pancreas (arrowhead).

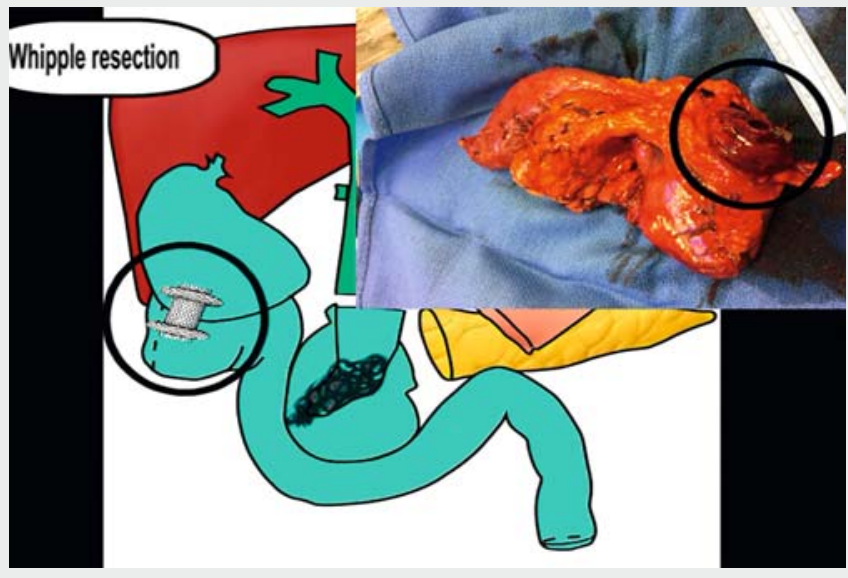

Video 1 Endoscopic ultrasound-guided gallbladder drainage as a bridge-to-surgery biliary decompression in a patient with a resectable distal biliary stricture. Source for the graphical details in the video: Federico Amata

\section{Acknowledgment}

We thank Federico Amata for graphic assistance.

\section{Competing interests}

None
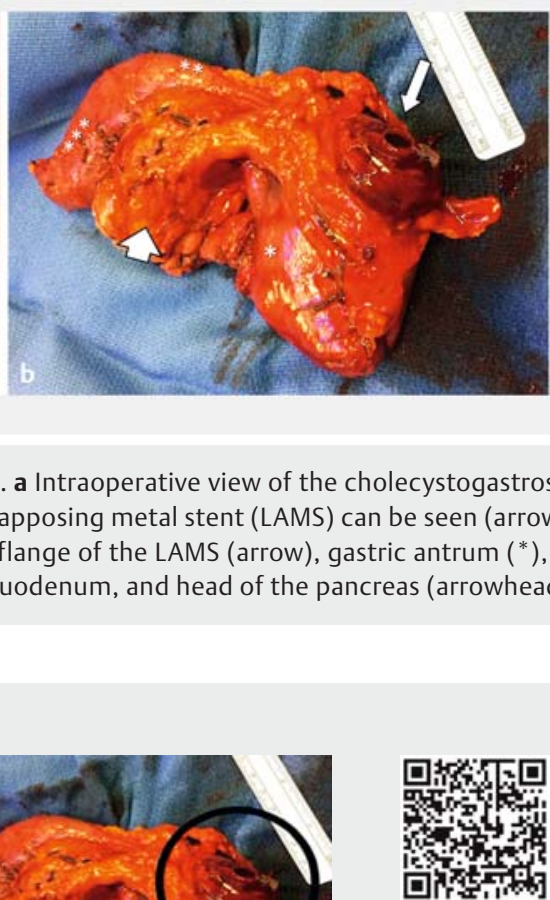

2 Abdominal Surgery and Organ Transplantation Unit, Department for the Treatment and Study of Abdominal Diseases and Abdominal Transplantation, IRCCSISMETT, Palermo, Italy

Corresponding author

\section{Dario Ligresti, MD}

Endoscopy Service, Department of Diagnostic and Therapeutic Services, IRCCS ISMETT - UPMC, Via E. Tricomi 5, 90127 Palermo, Italy

Fax: +39-091-2192400

dligresti@ismett.edu

\section{Reference}

[1] Imai H, Kitano M, Omoto $\mathrm{S}$ et al. EUS-guided gallbladder drainage for rescue treatment of malignant distal biliary obstruction after unsuccessful ERCP. Gastrointest Endosc 2016; 84: 147-151

\section{Bibliography}

DOI https://doi.org/10.1055/a-0754-1847

Published online: 7.11.2018

Endoscopy 2019; 51: 94-95

(c) Georg Thieme Verlag KG

Stuttgart · New York

ISSN 0013-726X

\section{ENDOSCOPY E-VIDEOS \\ https://eref.thieme.de/e-videos}

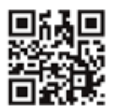

Endoscopy E-Videos is a free access online section, reporting on interesting cases and new

techniques in gastroenterological endoscopy. All papers include a high quality video and all contributions are freely accessible online.

\section{Amata', Fabio Cipolletta ${ }^{1}$, Salvatore} Gruttadauria $^{2}$, Davide Cintorino ${ }^{2}$, Mario Traina ${ }^{1}$

1 Endoscopy Service, Department of Diagnostic and Therapeutic Services, Istituto Mediterraneo per i Trapianti e Terapie ad alta specializzazione (IRCCS-ISMETT), Palermo, Italy
This section has its own submission website at

https://mc.manuscriptcentral.com/e-videos 